\title{
Impact of Foliar Fungicides on Gibberella Ear Rot and Deoxynivalenol Levels in Indiana Corn
}

\author{
N. R. Anderson, M. P. Romero Luna, J. D. Ravellette, and K. A. Wise, ${ }^{\dagger}$ Department of Botany and Plant Pathology, Purdue University, \\ West Lafayette, IN 47907
}

Accepted for publication 8 August 2017.

\begin{abstract}
Gibberella ear rot, caused by the fungus Fusarium graminearum (Schawbe), can cause significant yield reductions in corn (Zea mays L.) as well as reduce grain quality. Field experiments were conducted at two locations in Indiana to assess the impact of commercially available fungicides on Gibberella ear rot severity and deoxynivalenol (DON) accumulation in hybrid corn grain. The experiments were arranged in a random complete block design with both inoculated and noninoculated treatments. Three fungicides-azoxystrobin + propiconazole, prothioconazole, and pyraclostrobin-were applied during silking (R1), and Gibberella ear rot severity, DON accumulation

in grain, and corn yield were measured. Inoculated treatments had higher disease severity and DON and lower yield $(P<0.001)$ compared with noninoculated treatments. Fungicides reduced Gibberella ear rot severity in two location-years, but did not reduce DON in those experiments. All other fungicide treatments in all locations and years did not reduce disease severity or DON when compared with treatments not sprayed with fungicide. No fungicide increased DON levels in grain in any location or year. These results indicate that fungicide applications during the silking stage of corn may not consistently reduce DON levels in hybrid corn.
\end{abstract}

Fusarium graminearum (Schwabe) is an important pathogen of field corn (Zea mays L.) in Indiana, infecting ears, stalks, and seed (Sutton 1982; White 1999). The ear rot phase, referred to as Gibberella ear rot, initiates when the fungus infects corn ears during the early silking growth stage (Christenson and Schneider 1950; Reid et. al 1992; Warfield and Davis 1996). Signs of Gibberella ear rot include a fungal mat on the ear that has a pink to reddish color, and in severe cases, the whole ear becomes infected, and the husks become stuck to the ear (Sutton 1982; Woloshuk and Wise 2010). This disease can cause significant yield loss; recent estimates for the United States and Ontario, Canada, indicate that Gibberella ear rot reduces yield by over 1 million metric tons per year (Mueller and Wise 2014; Mueller and Wise 2015; Mueller et. al 2016). In addition to the ear mold, $F$. graminearum produces mycotoxins, including deoxynivalenol (DON; Marasa et al. 1984). Grain high in DON poses a risk to livestock since consuming DON can result in vomiting and feed refusal, particularly in swine. DON can reduce the value of the corn due to price dockage, or farmers may be unable to sell grain because of toxin levels that are above acceptable limits.

Gibberella ear rot management includes using moderately resistant hybrids and cultural practices such as tillage and crop rotation. However, there are currently no hybrids with complete resistance to Gibberella ear rot, and traditional cultural practices such as tillage are used less frequently in many corn production areas in the United States due to an increase in conservation tillage and no-tillage (Horowitz et. al 2010). In 2013, 34\% of Indiana farmers were producing corn under conservation tillage, which is almost 1 million ha of corn production in the state (Harmon 2015). While conservation tillage is a useful strategy to help minimize soil erosion, it aids in the survival of residue-borne fungal pathogens such as $F$. graminearum

${ }^{\dagger}$ Corresponding author. E-mail: kawise@purdue.edu

(C) 2017 The American Phytopathological Society by leaving more residue and available inoculum for the subsequent crop (Dill-Macky and Jones 2000; Pereyra et. al 2004). Additionally, F. graminearum disperses by air and wind (Maldonado-Ramirez et. al 2005; Schmale et. al 2006), and can cause Fusarium head blight in wheat (Triticum aestivum), which is another common field crop in Indiana. Therefore, ample sources of $F$. graminearum inoculum are present to potentially infect Indiana corn annually. Hybrid selection and tillage are employed to reduce risk of Gibberella ear rot prior to planting (Munkvold 2003), but until recently, there were no in-season management options, such as fungicides, available for use.

Since 2008, foliar fungicide use in corn has increased and specific fungicides have been promoted in corn for ear rot suppression (Romero Luna and Wise 2015; Wise and Mueller 2011). In 2013, prothioconazole, marketed as Proline (Bayer CropScience, Research Triangle Park, NC), was labeled for Gibberella ear rot and DON management. Prothioconazole is a demethylation inhibiting (DMI) fungicide, which blocks or prevents a fungus from producing essential sterol compounds such as ergosterol that are important for fungal membrane structure and function (Latin 2011; Mueller et. al 2013). Prothioconazole has upwardly systemic movement in the plant (Latin 2011) and is one of the most effective active ingredients for controlling Fusarium head blight and DON in wheat (Haidukowski et. al 2012; Jones 2000; Paul et. al 2008; Wegulo et. al 2011).

While the DMI fungicide class has been shown to reduce Fusarium head blight and DON levels in wheat (Freije and Wise 2015; Paul et. al 2008), members of another fungicide group, the Quinone-outside inhibitors (QoI; FRAC group 11), have been shown to increase DON levels in wheat when applied at the flowering growth stage (Ellner 2005; Nakajima 2010). This fungicide group is also widely used in corn production, and fungicide applications commonly occur during the tasseling and silking growth stages of corn (VT-R2), which corresponds to the flowering growth stage in wheat. However, the impact of QoI applications on DON accumulation in hybrid corn is not well known. Therefore, the objective of this research was to 
evaluate the efficacy of DMI and QoI fungicides on Gibberella ear rot severity and DON levels in corn in Indiana under inoculated and noninoculated conditions.

\section{Determining the Impact of Fungicides on Gibberella Ear Rot and Deoxynivalenol}

Research trials were established during the 2013 and 2014 growing seasons with trials near Lafayette, IN, at the Throckmorton Purdue Agricultural Center (TPAC) in 2013 and near Wanatah, IN, at the Pinney Purdue Agricultural Center (PPAC) in 2013 and 2014. Trials were arranged in a randomized complete block design with four replications using a $2 \times 3$ factorial, with level one as inoculation treatment (inoculated and noninoculated) and fungicide treatment as level two. Fungicides tested included the DMI fungicide prothiconazole (Proline, Bayer Crop Science), the QoI fungicide pyraclostrobin (Headline, BASF Corporation, Research Triangle Park, NC), and a QoI + DMI fungicide, azoxystrobin + propiconzaole (Quilt Xcel, Syngenta Crop Protection, Greensboro, NC).

Experiments were planted using a Kincaid plot planter (Kincaid, Haven, KS) at a rate of 79,070 seeds per hectare of Pioneer hybrid P32T85, which is rated as 3 for Gibberella ear rot on a rating scale of 1 to 9 , where 9 represents the highest level of resistance. Each year, corn followed soybean. Planting occurred on 22 May in 2013 at TPAC, and 2 May in both 2013 and 2014 at PPAC. Experimental plots were four rows wide (row spacing was $0.76 \mathrm{~m}$ ) by $9.1 \mathrm{~m}$ long, with the center two rows used for experimental measurements and the outer two rows as buffer. In all years, trials were conducted with standard agricultural practices for the area (Purdue Extension 2015), including a pre- and post-emergence herbicide application for weed management, and either a preplanting fertilization with nitrogen as ammonium nitrate at a rate of $168 \mathrm{~kg} \mathrm{~N} / \mathrm{ha}$, or postplant sidedressing. In 2013, the trial at TPAC was chisel plowed in the fall of 2012, and then in 2013 worked with a disc harrow on 15 May, and with a field cultivator on 22 May. The field at PPAC in 2013 was worked with a disc harrow on 30 April, then with a field cultivator with a harrow attached on 1 May. In 2014, the field at PPAC was worked using a one-pass tillage implement on 25 April.

Inoculum production and application. Fungal isolates used for inoculum production were three single-spore isolates of $F$. graminearum collected from different geographical locations within Indiana (09IN Decatur F3S1, 09IN Decatur F1S1, 10INSW S2U1-12). Isolates were removed from long-term storage at $-80^{\circ} \mathrm{C}$ and plated onto potato dextrose agar (Becton Dickson, Franklin Lakes, NJ) for 7 days at room temperature with a 12-h light/dark cycle. Liquid mung bean media was prepared by following a previously published method (Bai and Shaner 1996; Bai et. al 2000) with the exception that water was heated to 95 to $98^{\circ} \mathrm{C}$ but never allowed to boil. A $5 \mathrm{~mm}$ round plug from each 7-day-old culture of $F$. graminearum was added to a flask of the liquid mung bean media. The inoculated flasks were then placed on a shaker at $95 \mathrm{rpm}$ at room temperature with a 12-h light/dark cycle. After shaking for 21 days, the solution in the flasks was strained into a new flask using a medium-mesh metal kitchen strainer to remove large particulates. The resulting suspension was kept in clean, 3-liter bottles and the $F$. graminearum macroconidia concentration was quantified using a hemocytometer. The concentration was recorded and adjusted to 10,000 conidia $/ \mathrm{ml}$ with distilled water. After adjusting the concentration, all three isolates were mixed evenly prior to inoculation.

At corn growth stage R1, when the ears begin silking (Abendroth et. al 2011), $5 \mathrm{ml}$ of the conidial suspension $(10,000$ conidia/ml) was injected into all ears of plants within the center two rows of plots that were to receive inoculum using a modified auto-syringe (AllFlex USA, Dallas, TX; Anderson et al. 2016). The inoculum was applied $24 \mathrm{~h}$ after fungicide treatment application. Inoculations took place on 1 August at TPAC and on 19 July at PPAC in 2013; in 2014, the concentration of conidia was modified to $7,500 \mathrm{conidia} / \mathrm{ml}$ and applied on 25 July at PPAC.

Fungicide application. Fungicide was applied to experimental plots at corn growth stage R1 using a handheld boom sprayer (Research and Development Sprayers, Opelousas, LA) adjusted to a rate of spray of 61.3 liters/ha at $275.8 \mathrm{kPa}$. The hand-held boom was fitted with four TJ-VS 8002 (TeeJet Technologies, Springfield, IL) nozzles spaced $45.7 \mathrm{~cm}$ apart. Fungicides were applied according to these labeled rates: pyraclostrobin, $103.41 \mathrm{ml} / \mathrm{ha}$; prothioconazole, $202.46 \mathrm{ml} / \mathrm{ha}$; and azoxystrobin + propiconazole, $98.6 \mathrm{ml} / \mathrm{ha}+$ $85.46 \mathrm{ml} / \mathrm{ha}$. Preference, a nonionic surfactant (NIS; Winfield Solutions, Shoreview, MN) was added to the fungicide application at a concentration of $0.125 \%$ volume to volume $(\mathrm{v} / \mathrm{v})$. Fungicide treatments were sprayed $24 \mathrm{~h}$ prior to inoculum application.

Data collection. At harvest, 10 ears were arbitrarily sampled from each plot within the center two rows of each plot for disease ratings and DON testing. Sampled ears were husked and percent severity of Gibberella ear rot on each ear was rated using a percentage scale from 0 to 100 , with 0 being no fungal colonization on the ear and 100 being the entire ear area fully colonized. The remaining ears from the center two rows were harvested using a Kincaid plot combine (Kincaid, Haven, KS), which also measured moisture percentage, total weight, and test weight. Yield was calculated using the weight and moisture values from the combine as well as plot size and adjusted to $15.5 \%$ moisture. In 2014, the sampled ear weight, adjusted to $15.5 \%$ moisture, was also added to the harvested weight to obtain an adjusted yield value.

Mycotoxin testing. Sampled ears were shelled using an Agriculex SCS-2 sheller (Agriculex, Guelph, Ontario Canada), taking precautions to vacuum and brush out the sheller between each plot. The shelled corn was then ground using a Romer Labs series II grain mill (Romer Labs, Union, MO), again taking precautions to disassemble and clean the mill between each plot sample. Twenty grams of the resulting ground corn was weighed and tested for the level of DON present using Envirologix QuickTox kit for DON (Envirologix, Portland, ME) following the manufacturer's protocol. Briefly, $100 \mathrm{ml}$ of distilled water was added to each 20-g sample and shaken vigorously by hand. The mixture was allowed to settle into two layers after which $200 \mu \mathrm{l}$ of the top layer was removed and mixed with $800 \mu \mathrm{l}$ of DB6 buffer in a $1.7-\mathrm{ml}$ microcentrifuge tube. From this sample-buffer mixture, $200 \mu \mathrm{l}$ was removed and placed in a vial and a test strip placed into the liquid. The strips were left in the solution for three minutes, immediately after, DON levels were measured by placing the strips into the Envirologix QuickScan system to obtain a quantified reading of the sample in parts per million (ppm), with the limit of detection $0.2 \mathrm{ppm}$ to $10 \mathrm{ppm}$. When samples exceeded manufacturer's protocols for detection limits (10 ppm) additional dilutions were performed until an endpoint value for the DON concentration was reached.

Data analysis. The normal distribution and homogeneity of variance for the disease severity and DON data were verified using PROC UNIVARIATE in SAS software version 9.4 (SAS Institute Inc., Cary, NC). Disease severity values were arcsine transformed (arcsine-square-root transformation), while DON values were square root transformed (square-root transformation). Back-transformed means were presented after analysis. Data were analyzed using the generalized mixed model (GLIMMIX) in SAS v. 9.4. Mean separations were based on least square (LS) means test at the $P \leq 0.05$ level.

\section{Impact of Fungicides on Gibberella Ear Rot and Deoxynivalenol}

The location and year main effects and their interaction were highly significant for disease severity $(P<0.0001, P<0.0001$, 
$P<0.0001$, respectively) and yield $(P=0.0002, P=0.0321, P<$ 0.0001 , respectively). Year significantly affected DON $(P<$ $0.0001)$. Therefore, each experiment was analyzed separately by location and year.

TPAC field trials 2013. Treatment significantly affected disease severity $(P=0.0002), \mathrm{DON}(P<0.0025)$, and yield $(P<0.0009)$ at this location. Disease severity was significantly higher in inoculated treatments compared with noninoculated treatments (Fig. 1). Prothioconazole reduced disease severity compared with the inoculated, non-fungicide-treated control (Fig. 1). No other fungicide reduced disease severity compared with the non fungicide-treated controls (Fig. 1). DON levels were significantly higher in the inoculated treatment compared with the noninoculated treatment. Fungicide treatment did not impact DON levels within inoculated or noninoculated treatments compared with the non-fungicidetreated controls (Fig. 1). Higher yields were observed in the noninoculated versus inoculated treatments, with the exception of the inoculated prothioconazole treatment, which yielded the same as the noninoculated azoxystrobin + propiconazole treatment. However, no

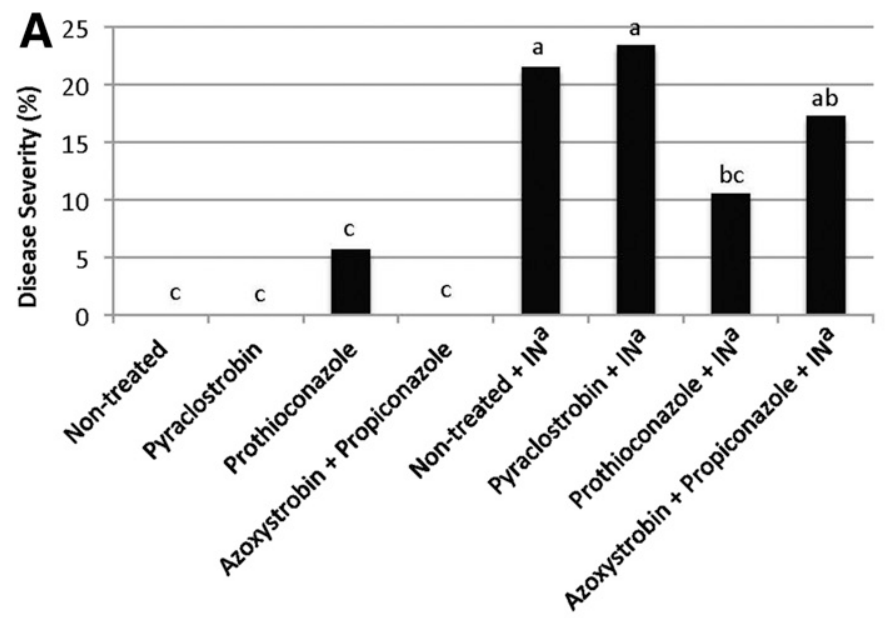

Fungicide + Inoculation treatment

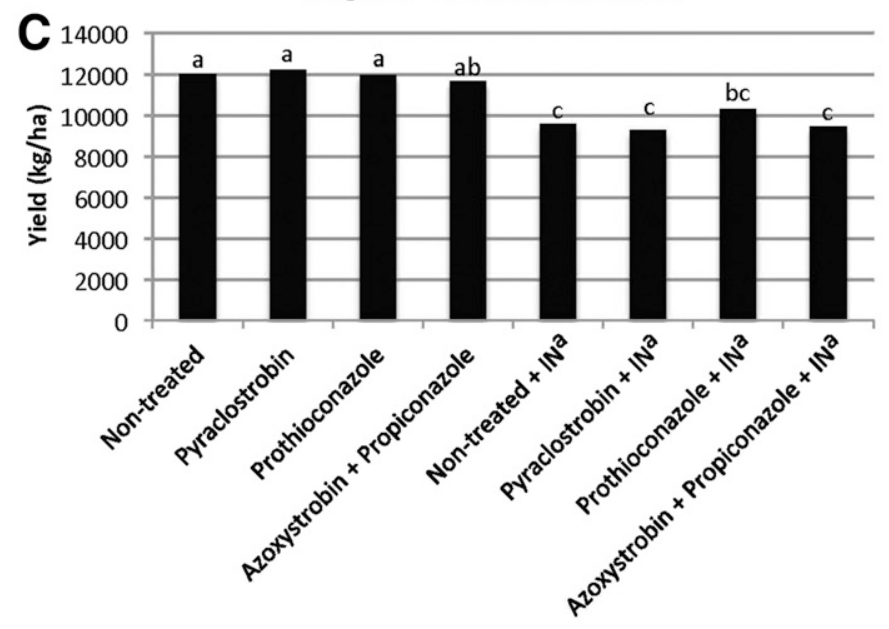

Fungicide + Inoculation treatment fungicide application increased yield when compared with the nonfungicide-treated controls (Fig. 1).

PPAC field trials 2013. Treatment significantly affected disease severity $(P<0.0001)$, DON $(P<0.0001)$, and yield $(P<0.0001)$. Disease severity was significantly higher in inoculated treatments compared with noninoculated treatments. Fungicide had no effect on disease severity, DON, or yield in noninoculated treatments, but in inoculated treatments, fungicides reduced disease severity compared with the nonfungicide treated control (Fig. 2). Despite a reduction in disease severity, fungicide did not reduce DON or increase yield in inoculated treatments compared with the nonfungicide treated control (Fig. 2).

PPAC field trials 2014. Treatment significantly affected disease severity $(P<0.0001)$, DON $(P<0.0079)$, and yield $(P<0.0001)$, with inoculated treatments having significantly higher disease severity and DON levels and lower yields compared with noninoculated plots. However, fungicide treatment did not decrease disease severity, DON, or increase yield in either inoculated or noninoculated treatments when compared with the nonfungicide control (Fig. 3).

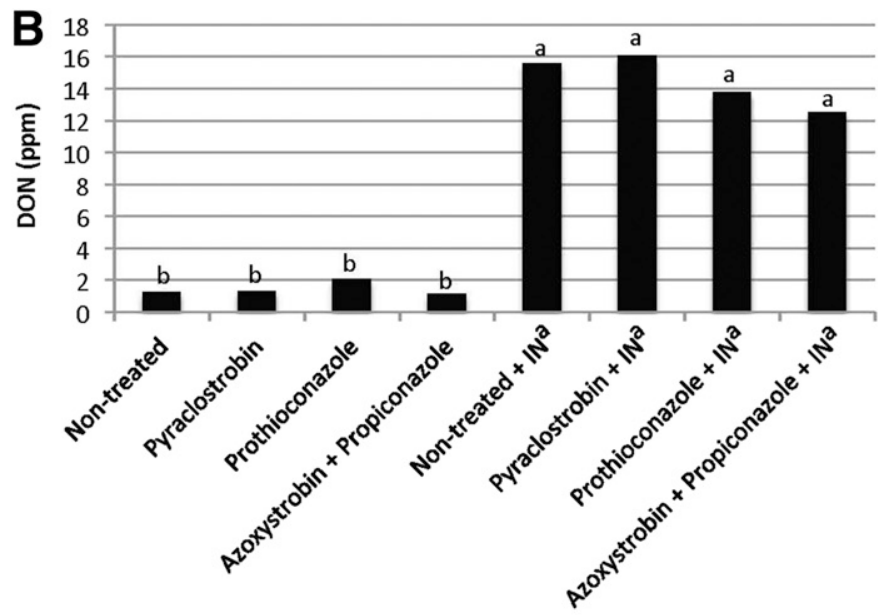

Fungicide + Inoculation Treatment

alN - Artificial inoculation of Fusarium graminearum at 10,000 conidia/mL at silking growth stage (R1).

FIGURE 1

Effect of inoculation and fungicide application on (A) Gibberella ear rot severity caused by Fusarium graminearum, (B) deoxynivalenol production (DON), and (C) yield under noninoculated and inoculated conditions at the Throckmorton Purdue Agricultural Center (TPAC) in Tippecanoe County, IN, in 2013. Values with the same letter are not significantly different within each treatment based on Least square (LS) means test $(P=0.05)$. 


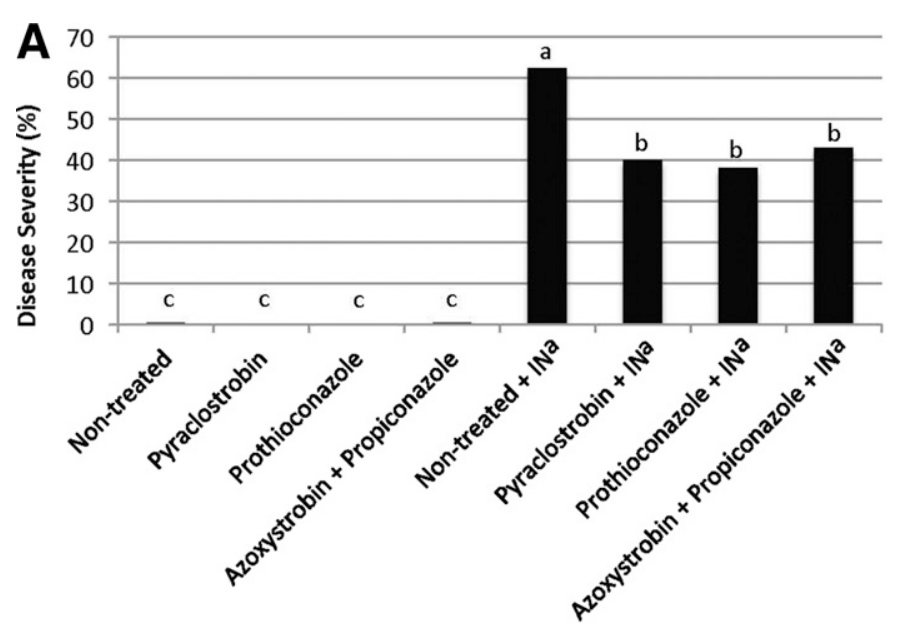

Fungicide + Inoculation treatment

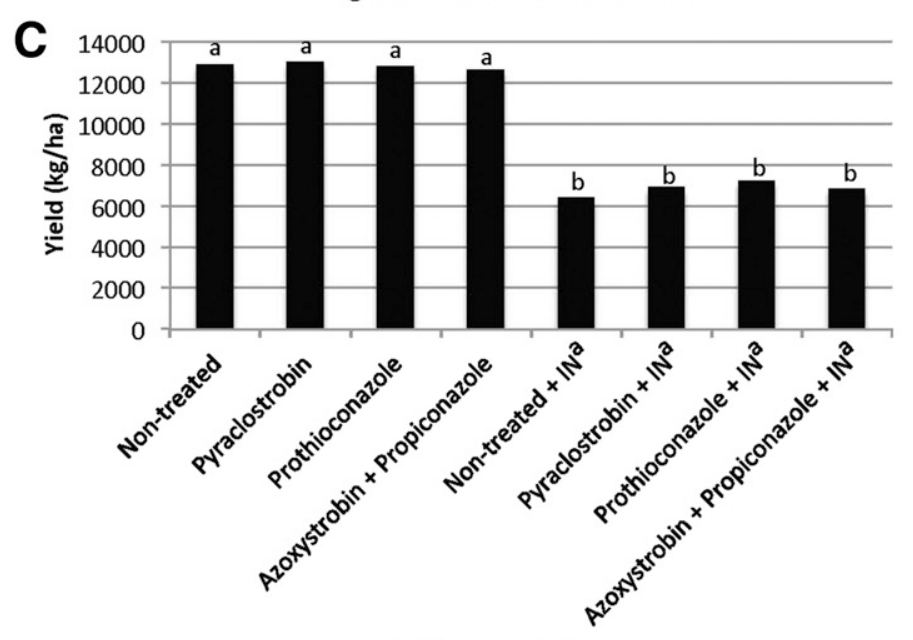

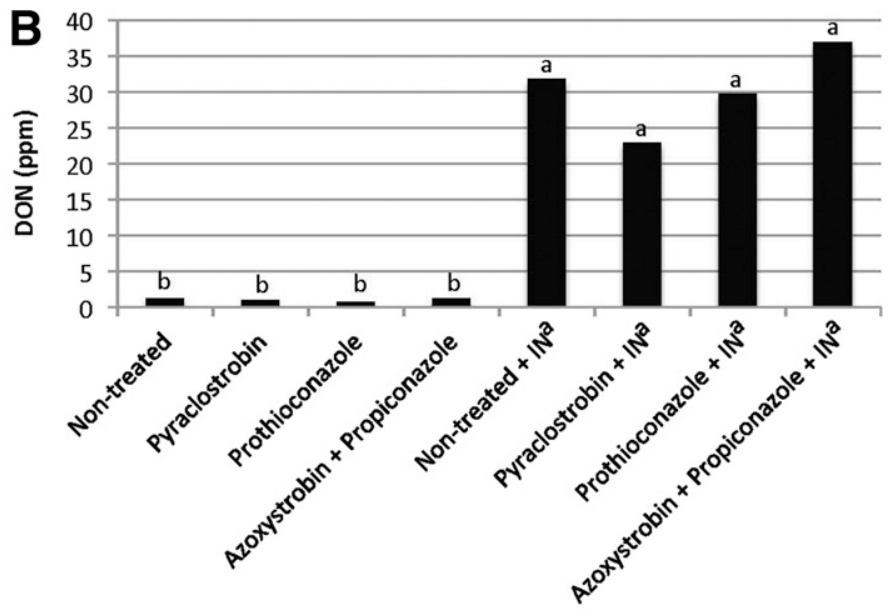

Fungicide + Inoculation treatment

Fungicide + Inoculation treatment

aIN - Artificial inoculation of Fusarium graminearum at 10,000 conidia/mL at silking growth stage (R1).

\section{FIGURE 2}

Effect of inoculation and fungicide application on (A) Gibberella ear rot severity caused by Fusarium graminearum, (B) deoxynivalenol production (DON), and (C) yield under noninoculated and inoculated conditions at the Purdue Agricultural Center (PPAC), in LaPorte County, IN, in 2013. Values with the same letter are not significantly different within each treatment based on Least square (LS) means test $(P=0.05)$.

Within inoculated treatments, pyraclostrobin alone and azoxystrobin + propiconazole had significantly higher disease severity and azoxystrobin + propiconazole had lower yields compared with the inoculated, nonfungicide-treated control (Fig. 3).

\section{Fungicide Use Recommendations for Gibberella Ear Rot and Deoxynivalenol Management}

Our research demonstrated that the foliar fungicides tested reduced Gibberella ear rot severity under inoculated conditions in several experimental locations. Prothioconazole, which is labeled for suppression of Gibberella ear rot and DON management, did reduce disease severity in inoculated treatments at two locationyears, but no fungicide reduced DON levels in any location or year.

Other studies have also examined the role of foliar fungicides in Gibberella ear rot control. In Wisconsin, applications of fungicide at the six-leaf stage (V6) followed by an application at tasseling (VT) had no significant effect on Gibberella ear rot severity (Smith et al. 2015). However, Gibberella ear rot levels in this trial were low, which may have impacted the results. In contrast, in South America, fungicides reduced Gibberella ear rot by up to $52 \%$ when applied two days before or after silk emergence (Andriolli et al. 2016). However, neither of these previous studies examined the role of fungicides on DON. The impact of fungicide on DON accumulation is important, since farmers experience significant economic loss when harvested grain has high levels of DON, causing dockage at the point of sale and limiting supply through agricultural feed and ethanol markets (Munkvold 2014). Therefore, fungicides that reduce disease severity but do not consistently reduce DON are of limited value for Gibberella ear rot management.

The inconsistency in Gibberella ear rot control observed in this and previous trials may be due to fungicide application method and fungicide movement in corn tissue. Previous research examining fungicide efficacy against another ear rot pathogen, Stenocarpella maydis, indicated that although labeled fungicides can control $S$. maydis in vitro, no product consistently reduced disease severity when applied through traditional overhead field application methods (Romero Luna and Wise 2015). The authors suggested that the application method and fungicide movement in the plant likely 


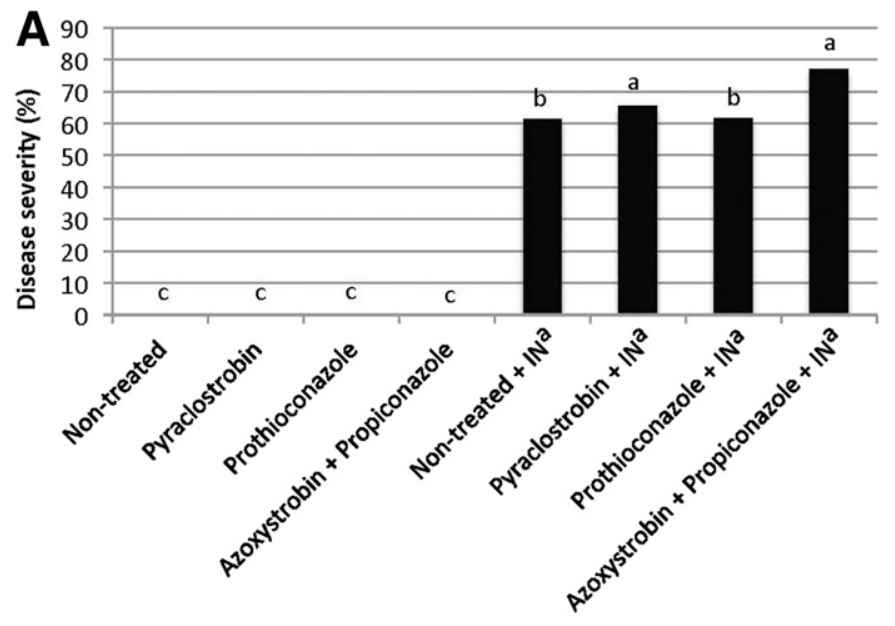

Fungicide + Inoculation treatment

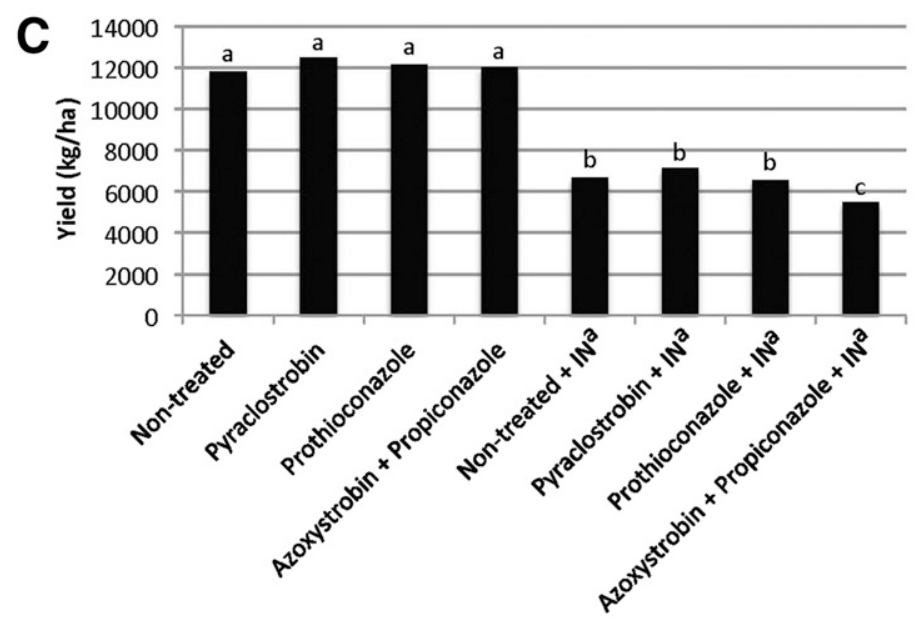

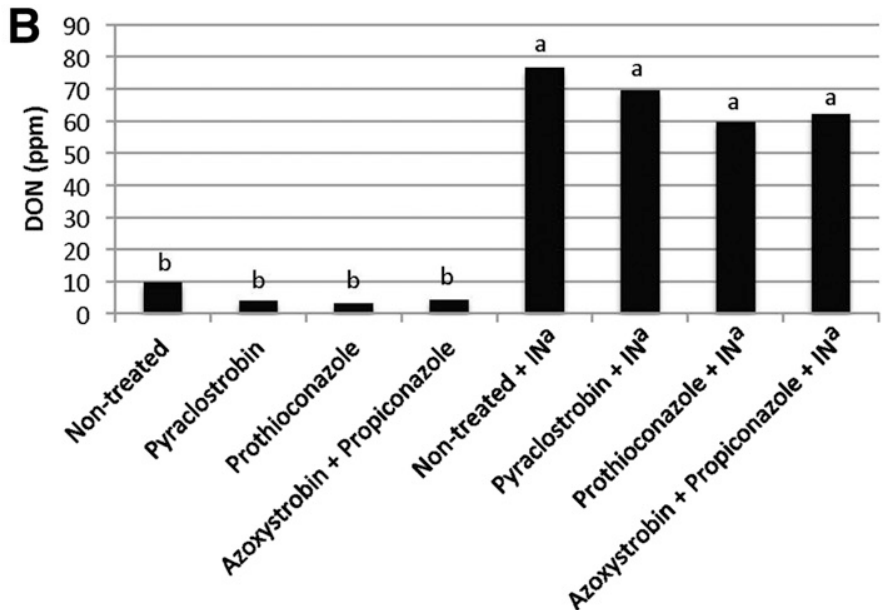

Fungicide + Inoculation treatment

Fungicide + Inoculation treatment

aIN - Artificial inoculation of Fusarium graminearum at 7,500 conidia/mL at silking growth stage (R1)

\section{FIGURE 3}

Effect of inoculation and fungicide application on (A) Gibberella ear rot severity caused by Fusarium graminearum, (B) deoxynivalenol production (DON), and (C) yield under noninoculated and inoculated conditions at the Purdue Agricultural Center (PPAC), in LaPorte County, IN, in 2014. Values with the same letter are not significantly different within each treatment based on Least square (LS) means test $(P=0.05)$.

influence fungicide efficacy against ear rots. None of the fungicides used in our experiment are fully systemic fungicides, but are either a local penetrant, meaning they are not transported far from the site of uptake or contact, or are acropetal penetrants, which move upwards in the plant protecting the area of contact and newer growth (Latin 2011; Vincelli 2002). This means that these fungicides, if able to penetrate the thick corn husk tissue, are moving up into the tip of the ear, and may not be able to consistently halt fungal growth and infection. The husk barrier may also explain why fungicide active ingredients that are effective against Fusarium head blight and DON on wheat, which have exposed heads, do not consistently reduce Gibberella ear rot and DON in corn. More research is needed on how hybrid, environment, and corn characteristics such as ear position and husk tissue influence fungicide penetration and efficacy against ear rot pathogens.

Although QoI fungicides can increase DON when applied at anthesis, or flowering in wheat (Wegulo 2012; Yoshida and Nakajima 2010), the QoI fungicides tested in our experiment did not increase DON at a similar flowering timing in corn. This difference could be due to the aforementioned fungicide movement and different tissue exposure between corn and wheat, and requires further investigation.

Foliar fungicides, such as those tested here, are an added expense in corn production, and can be effective in-season management tools for foliar diseases such as gray leaf spot (Cercospora zeaemaydis) or northern corn leaf blight (Exserohilum turcicum) in Indiana; however, our research shows that in areas where Gibberella ear rot and DON are common, these fungicides do not consistently reduce DON levels under high disease pressure, negating the economic benefit of using these products for this intended use. We recommend that farmers continue to manage Gibberella ear rot using cultural methods, such as hybrid selection, crop rotation, and residue management.

\section{Acknowledgments}

This research was funded in part by the USDA North Central Integrated Pest Management proposal number 2011-00521, entitled "Integrated Management Plans for Western Bean Cutworm and Gibberella Ear Rot." 
The authors thank J. Leuck and J. Young for assistance with field trial set-up and maintenance, and J. Corl, R. Fister, G. Hollandbeck, K. Lewis, and $\mathrm{K}$. Raun for assistance with inoculation, fungicide applications, data collection, mycotoxin testing and harvest.

\section{Literature Cited}

Abendroth, L. J., Elmore, R. W., Boyer, M. J., and Marlay, S. K. 2011. Corn growth and development. Ext. Publ. PMR-1109. Iowa State Univ., Ames, IA.

Anderson, N. R., Ravellette, J. D., and Wise, K. A. 2016. Improved method for injecting fungal inoculum into corn ears. Plant Health Prog. 17:163-166.

Andriolli, C. F., Casa, R. T., Kuhnem, P. R., Bogo, A., Zancan, R. L., and Reis, E. L. 2016. Timing of fungicide application for the control of Gibberella ear rot of maize. Trop. Plant Pathol. 41:264-269.

Bai, G.-H., and Shaner, G. 1996. Variation in Fusarium graminearum and cultivar resistance to wheat scab. Plant Dis. 80:975-979.

Bai, G.-H., Shaner, G., and Ohm, H. 2000. Inheritance of resistance to Fusarium graminearum in wheat. Theor. Appl. Genet. 100:1-8.

Christenson, C. M., and Schneider, C. L. 1950. European corn borer (Pyrausta nubilalis $\mathrm{H} \mathrm{bn}$.) in relation to shank, stalk, and ear rots of corn. Phytopathology 40:284-291.

Dill-Macky, R., and Jones, R. K. 2000. The effect of previous crop residues and tillage on Fusarium head blight of wheat. Plant Dis. 84:71-76.

Ellner, F. M. 2005. Results of long-term field studies into the effect of strobilurin containing fungicides on the production of mycotoxins in several winter wheat varieties. Mycol. Res. 21:112-115.

Freije, A. N., and Wise, K. A. 2015. Impact of Fusarium graminearum inoculum availability and fungicide application timing on Fusarium head blight in wheat. Crop Prot. 77:139-147.

Haidukowski, M., Visconti, A., Perrone, G., Vanadia, S., Pancaldi, D., Covarelli, L., Balestrazzi, R., and Pascale, M. 2012. Effect of prothioconazole-based fungicides on Fusarium head blight, grain yield, and deoxynivalenol accumulation in wheat under field conditions. Phytopathol. Mediterr. 51:236-246.

Harmon, L. 2015. Indiana statewide tillage: 1990-2015. Indiana State Dept. of Agric., Indianapolis, IN. http://www.in.gov/isda/files/No_Till_Trends_19902015_Statewide.pdf

Horowitz, J., Ebel, R., and Ueda, K. 2010. "No-Till" farming is a growing practice. EIB-70. USDA-ERS, Washington, DC. http://ageconsearch.umn. edu/bitstream/96636/2/EIB70.pdf

Jones, R. K. 2000. Assessments of Fusarium head blight of wheat and barley in response to fungicide treatment. Plant Dis. 84:1021-1030.

Latin, R. 2011. A Practical Guide to Turfgrass Fungicides. American Phytopathological Society, St. Paul, MN.

Maldonado-Ramirez, S. L., Schmale, D. G., III, Shields, E. J., and Bergstrom, G. C. 2005. The relative abundance of viable spores of Gibberella zeae in the planetary boundary layer suggest the role of long-distance transport in regional epidemics of Fusarium head blight. Agric. For. Meteorol. 132:20-27.

Marasa, W. F. O., Nelson, P. E., and Toussoun, T. A. 1984. Toxigenic Fusarium Species: Identity and Mycotoxicology. The Pennsylvania State Univ. Press, University Park, PA.

Mueller, D. S., Sisson, A., and Wise, K. A. 2016. Corn disease loss estimates from the United States and Ontario, Canada, 2015. CPN-2007-14-W. Crop Protection Network.

Mueller, D. S., and Wise, K. A. 2014. Corn disease loss estimates from the United States and Ontario, Canada - 2013. Diseases of Corn. BP-96-13-W. Purdue Univ., West Lafayette, IN.
Mueller, D. S., and Wise, K. A. 2015. Corn disease loss estimates from the United States and Ontario, Canada - 2014. Diseases of Corn. BP-96-14-W. Purdue Univ., West Lafayette, IN.

Mueller, D. S., Wise, K. A., Dufault, N. S., Bradley, C. A., and Chilvers, M. I. 2013. Fungicides for field crops. American Phytopathological Society, St. Paul, MN.

Munkvold, G. 2014. Crop management practices to minimize the risk of mycotoxins contamination in temperate-zone maize. Pages 59-77 in: Mycotoxin Reduction in Grain Chains. J. F. Leslie and A. F. Logreico, eds. John Wiley and Sons, Hoboken, NJ.

Munkvold, G. P. 2003. Cultural and genetic approaches to managing mycotoxins in maize. Annu. Rev. Phytopathol. 41:99-116.

Nakajima, T. 2010. Fungicides application against Fusarium head blight in wheat and barley for ensuring food safety. Pages 139-156 in: Fungicides. O. Carisse, ed. InTech, Rijeka, Croatia.

Paul, P. A., Lipps, P. E., Hershman, D. E., McMullen, M. P., Draper, M. A., and Madden, L. V. 2008. Efficacy of triazole-based fungicides for Fusarium head blight and deoxynivalenol control in wheat: A multivariate meta-analysis. Phytopathology 98:999-1011.

Pereyra, S. A., Dill-Macky, R., and Sims, A. L. 2004. Survival and inoculum production of Gibberella zeae in wheat residue. Plant Dis. 88:724-730.

Reid, L. M., Bolton, A. T., Hamilton, R. I., Woldemariam, T., and Mather, D. E. 1992. Effect of silk age on resistance of maize to Fusarium graminearum. Can. J. Plant Pathol. 14:293-298.

Romero Luna, M. P., and Wise, K. A. 2015. Timing and efficacy of fungicide applications for Diplodia ear rot management in corn. Plant Health Prog. 16: 123-131.

Purdue Extension. 2015. Corn and Soybean Field Guide, 2015 Edition. ID-179. Purdue Crop Diagnostic Training and Res. Center, and Purdue Pest Manage. Prog., West Lafayette, IN.

Schmale, D. G., III, Leslie, J. F., Zeller, K. A., Saleh, A. A., Shields, E. J., and Bergstrom, G. C. 2006. Genetic structure of atmospheric populations of Gibberella zeae. Phytopathology 96:1021-1026.

Smith, D. L., Chapman, S., and Jensen, B. 2015. Evaluation of fungicide for control of diseases of dent corn in Wisconsin, 2014. Plant Dis. Manage. Rep. 9:FC027.

Sutton, J. C. 1982. Epidemiology of wheat head blight caused and maize ear rot caused by Fusarium graminearum. Can. J. Plant Pathol. 4:195-209.

Vincelli, P. 2002. Q $\mathrm{I}$ (Stobilurin) fungicides: Benefits and risks. Plant Health Instr. doi:10.1094/PHI-I-2002-0809-02

Warfield, C. Y., and Davis, R. M. 1996. Importance of the husk covering on the susceptibility of corn hybrids to Fusarium ear rot. Plant Dis. 80:208-210.

Wegulo, S. N. 2012. Factors influencing deoxynivalenol accumulation in small grain cereals. Toxins (Basel) 4:1157-1180.

Wegulo, S. N., Bockus, W. W., Nopsa, J. H., De Wolf, E. D., Eskridge, K. M., Peiris, K. H. S., and Dowell, F. E. 2011. Effects of integrating cultivar resistance and fungicide applications on Fusarium head blight and deoxynivalenol in winter wheat. Plant Dis. 95:554-560.

White, D. G., ed. 1999. Compendium of Corn Diseases, 3rd Ed. American Phytopathological Society, St Paul, MN.

Wise, K., and Mueller, D. 2011. Are fungicides no longer just for fungi? An analysis of foliar fungicide use in corn. APS Feat.

Woloshuk, C., and Wise, K. 2010. Diseases of corn: Gibberella ear rot. Ext. Publ. BP-77-W. Purdue Univ., West Lafayette, IN.

Yoshida, M., and Nakajima, T. 2010. Deoxynivalenol and nivalenol accumulation in wheat infected with Fusarium graminearum during grain development. Phytopathology 100:763-773. 